\title{
RECUPERAR LA ESENCIA DEL APOSTOLADO INTELECTUAL*
}

\begin{tabular}{c}
\hline Luis Solari de la Fuente* \\
Universidad Católica Sedes Sapientiae \\
lsolari@ucss.edu.pe
\end{tabular}

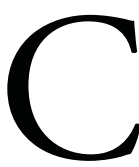

on mi saludo a todos, agradezco a los organizadores de la II Feria del Libro Católico por su gentil invitación para compartir con ustedes algunas reflexiones sobre el apostolado intelectual. Asimismo, mi agradecimiento a los distinguidos miembros de la mesa, Monseñor José Luis del Palacio y al profesor Paolo Musso, por su generosidad de compartirla conmigo.

En la misma semana de noviembre de 1989 se produjeron dos cambios que marcaron el inicio de la construcción de un mundo nuevo. El lunes 6, cambió la economía mundial con la creación formal del Foro de Cooperación Asia Pacífico-APEC. De igual forma, entre el jueves 9 y el

* El presente texto fue parte de la disertación realizada en la Conferencia "Apostolado Intelectual: Ciencias, Humanidades y Fe" llevada a cabo en la II Feria del Libro Católico. Este evento fue organizado por la Facultad de Teología Pontificia y Civil de Lima del 26 al 30 de mayo de 2015.

** Luis Solari de la Fuente es decano de la Facultad de Ciencias de la Salud de la Universidad Católica Sedes Sapientiae. 
viernes 10, se derrumbaría el Muro de Berlín para iniciar un nuevo cambio político en la estructura del poder mundial.

Desde entonces han pasado 26 ańos. Estaba pronosticado que, en el año 2016, China superaría a Estados Unidos en Paridad de Poder Adquisitivo (PPA) (en inglés, PPP, por sus siglas Purchasing Power Parity). Tal superación se adelantó, ya que fue anunciada por el Fondo Monetario Internacional en octubre 2014 (FMI, 2014). Otro pronóstico señala que, en el año 2025, China superará a Estados Unidos en gasto de defensa, con lo que se convertirá en el país más poderoso del planeta.

De esa forma, en apenas 36 años, se habrá diseñado la base de lo que será el siglo en curso. A lo largo de ese mismo lapso, la Iglesia ha transitado con el papa peregrino, el que estaba con todos; luego, le sucedió al papa de la fe y la razón hasta llegar al papa de la misericordia, Francisco. Todos estamos inmersos en este esplendoroso proceso que conduce el Señor de la Historia, Nuestro Señor.

Sin lugar a dudas, estos grandes cambios están impregnados por otros componentes que menciono a continuación: (a) la expansión y rapidez de las comunicaciones, (b) la movilización de personas y (c) la aparición de nuevas amenazas, entre otros. Sin embargo, la expansión del conocimiento es, indudablemente, el acompañante más espectacular de este gran cambio. Dicho desarrollo conlleva una impresionante expansión tecnológica y, a la vez, una veloz obsolescencia de la tecnología para dejar paso a otra más nueva, fruto de nuevo conocimiento.

Es evidente que ante tal escenario surgen, entonces, múltiples tareas, que ya no pueden ser acometidas con la discrecionalidad de un desafio, sino como un deber. Este deber ineludible es el de contribuir al mundo nuevo en formación, tanto en la construcción del mismo como protagonistas, así 
como en la formación de quienes nos seguirán en el tiempo en tal tarea. No podemos, pues, ser solo espectadores de este vertiginoso cambio y tampoco podemos evadir la responsabilidad de que, teniendo cerca de 220 universidades e institutos católicos en América Latina, seamos el territorio más desigual (léase injusto) del planeta y el segundo territorio más corrupto.

Es en esta ubicación histórica que considero debemos contemplar el tema del apostolado intelectual, en la investigación, en la enseñanza y en la formación de los estudiantes. De igual manera, es usual que cuando se habla del apostolado intelectual, se vaya más hacia lo intelectual y se deja por sentado que lo de apostolado es un sobreentendido por quienes abrazan tal menester, pero no es así. Ahora bien, el papa Francisco nos llama a la reflexión sobre el particular en su Exhortación Apostólica Evangelii gaudium (EG):

La misión en el corazón del pueblo no es una parte de mi vida, o un adorno que me puedo quitar; no es un apéndice o un momento más de la existencia. Es algo que yo no puedo arrancar de mi ser si no quiero destruirme. Yo soy una misión en esta tierra, y para eso estoy en este mundo. Hay que reconocerse a sí mismo como marcado a fuego por esa misión de iluminar, bendecir, vivificar, levantar, sanar, liberar. Allí aparece la enfermera de alma, el docente de alma, el político de alma, esos que han decidido a fondo ser con los demás y para los demás. Pero si uno separa la tarea por una parte y la propia privacidad por otra, todo se vuelve gris y estará permanentemente buscando reconocimientos o defendiendo sus propias necesidades. Dejará de ser pueblo. (273) 
A partir de lo mencionado, cabe formular, entonces, varias preguntas. ¿Cómo podría ejercerse el apostolado intelectual sin ser apóstol, sin haber pasado por el encuentro con Jesús, sin haberse convertido en discípulo misionero? ¿Cómo podría ser docente de alma, sin ser una misión en esta tierra? ¿Puedo ser una misión sin el Divino Encuentro? ¿Cómo podría una persona en el ejercicio del apostolado intelectual transmitir conocimiento sin el ejercicio de las gracias del entendimiento y la sabiduría, que derivan del proceso encuentro-conversión-discipulado-misión?

Algunas respuestas las proporciona el papa Francisco. Precisamente, podemos encontrarlas en su primera Carta Encíclica, Lumen fidei (LF):

Para la fe, Cristo no es sólo aquel en quien creemos, la manifestación máxima del amor de Dios, sino también aquel con quien nos unimos para poder creer. La fe no sólo mira a Jesús, sino que mira desde el punto de vista de Jesús, con sus ojos: es una participación en su modo de ver. (18)

En la fe, el «yo» del creyente se ensancha para ser habitado por Otro, para vivir en Otro, y así su vida se hace más grande en el Amor. En esto consiste la acción propia del Espíritu Santo. (21)

Quien ha sido transformado de este modo adquiere una nueva forma de ver, la fe se convierte en luz para sus ojos. (22)

Tomando en cuenta estas palabras del papa, ¿cómo podría alguien, en este vertiginoso mundo actual, ejercer el apostolado intelectual sin esa nueva forma de ver, que solo se obtiene a partir del Divino Encuentro? Es imposible, entonces, quedarse con lo intelectual soslayando lo de apostolado, como probablemente haya venido sucediendo en no pocos de nuestros centros educativos. Si no 
hubiese sido así, América Latina no sería territorio de vergüenza por lo antes mencionado: injusticia y corrupción. Esto me lleva a la necesidad urgente de replantear en nuestros centros de formación el tema del apostolado intelectual.

Por otro lado, es indistinto el terreno o el área temática en que se desarrolle el apostolado intelectual. Esto se debe a que el cambio que vivimos abarca ampliamente las ciencias y las humanidades. Por tanto, seguir separando estos aspectos del conocimiento puede contribuir a fragmentarlo aún más y así entorpecer el poder apreciar la integralidad de la realidad.

Precisamente, la separación absoluta de las ciencias y las humanidades se asemeja a la pretensión, metafórica por cierto, de querer separar el agua del agua. Ciencias y humanidades son aspectos de la verdad, entendida esta como el magnífico conjunto de todo lo que es, aunque aún no se le perciba con nuestros sentidos, aunque aún no se le descubra. Por esa razón, el apostolado intelectual es, en realidad, el apostolado de la verdad. ¿Se puede tener acceso a la plenitud de la verdad sin el Encuentro con Aquel en quien existe todo lo que es, con Aquel que es la Verdad? Definitivamente, no.

Para apoyar lo planteado anteriormente, puede recurrirse a otra importante reflexión. Albert Einstein, no creyente, lo testimonió con absoluta claridad:

Tener el conocimiento y el sentimiento de que lo que es impenetrable para nosotros realmente existe, que se manifiesta en la suprema sabiduría y en la más radiante belleza que nuestras torpes facultades solo pueden comprender en sus formas más primitivas, está en el centro de toda verdadera religiosidad. (1930, p. 194) 
Por otra parte, es totalmente distinto al apostolado intelectual, la actividad de un intelectual que desarrolla sus actividades en espacios de fe. Este puede transitar por esos espacios y cumplir diligentemente sus compromisos y obligaciones. Producirá en el tiempo otros intelectuales que puedan desarrollar sus actividades pulcramente. Asimismo, la formación modélica que brindará será la de la eficiencia y aún la de la justicia como fruto de un antropocentrismo presente en la existente cultura de derechos humanos.

Pero si el apostolado intelectual consistiese solo en buscar, descubrir y transmitir la verdad, no sería apostolado. El apostolado intelectual incluye consustancialmente la guía al descubrimiento de la donación de sí. Es precisamente esta donación de sí, la caritas, que en el proceso de la búsqueda y el servicio a los otros impulsa hacia la búsqueda de la verdad, más aún, hacia el Encuentro con Aquel en quien existe todo lo que es, Aquel que es la Verdad. Fue tan bien explicado este misterio por Benedicto XVI en las enseñanzas de su Carta Encíclica Caritas in veritate, que podría ser sintetizado en la siguiente frase: de la caridad en la verdad a la verdad en la caridad.

El apóstol intelectual, fruto del encuentro-conversión-discipuladomisión, propondrá permanentemente a Jesús como modelo. Es desde allí que también cumplirá diligentemente sus obligaciones y compromisos, pero por estar impregnado de un teoantropocentrismo, transmitirá el sentido de la justicia fundada no solo en la verdad sino también —indisolublementedesde la fraternidad, al ser todos hijos de un mismo Padre. También, podrá naturalmente integrar el conocimiento desde la verdad para un entendimiento de la integralidad de la realidad. Asimismo, le será imposible separar la razón de la fe, pudiendo integrarlas unitariamente con la caritas, para transmitir 
que esta última es como el cuerpo central de un ave, mientras que la fe y la razón son como sus alas.

Ahora bien, san Juan Pablo II refiere dicho aspecto en un imprescindible documento para las universidades católicas. Se trata de la Constitución Apostólica Ex Corde Ecclesiae (ECE) promulgada en 1990. Para el santo, es esta mencionada dimensión del apostolado intelectual la que permite, al que la ejerce, "unificar existencialmente en el trabajo intelectual dos órdenes de realidades [...]: la búsqueda de la verdad y la certeza de conocer ya la fuente de la verdad" (1).

Un aplicado estudiante, formado por un apóstol intelectual, al estar fundamentada su formación en la caritas/donación, vivirá una auténtica transformación y asumirá naturalmente, desde la fraternidad, el ejercicio del principio de subsidiaridad. Desde este, le será natural la participación protagónica en la Creación, en el nuevo mundo en formación, y será parte de los nuevos hombres y las nuevas mujeres que harán, recordando lo escrito en el Documento de Aparecida (DA), "converger en los pueblos ideales y poderosas energías morales y religiosas" (538), para que hayan nuevas estructuras.

Es por ello indispensable que en los centros donde se formen esos nuevos protagonistas del mundo, se desarrollen sistemas de voluntariado. Con estos, se alentaría a que los comprometidos puedan descubrir que dicho voluntariado no consiste en entregar algo o el tiempo propio, sino en entregarse uno mismo a la vez que se descubre el vivir el principio de subsidiaridad. Este último, decisivamente, radica en vivir hacia y para los demás

La acción del apostolado intelectual no solo es buscar la verdad, descubrirla y comunicarla en todos los campos del conocimiento, a la vez que prepara hombres y mujeres con sólidos principios cristianos que les motiven a vivir en la coherencia de una fe fiel. Además de todo lo anterior, 
incluye la generación de nuevo conocimiento para "ayudar a la iglesia a dar respuesta a los problemas y exigencias de cada época” (ECE 31). En suma, el apostolado intelectual también tiene esta estupenda finalidad: generar nuevo conocimiento que ayude a la evangelización de los pueblos.

Gracias por haberme permitido estas reflexiones sobre el apostolado intelectual, que creo debe ser redimensionado a su verdadero esplendor: el ser la noble tarea humana de buscar, descubrir y transmitir la verdad no desde el intelecto, sino desde la Fuente de la Verdad reflejada en el intelecto. Incluso, el propio Albert Einstein acertó intuitivamente en ello cuando afirmó:

La más bella y profunda emoción que nos es dado sentir es la sensación de lo místico. Ella es la que genera toda verdadera ciencia. El hombre que desconoce esa emoción, que es incapaz de maravillarse y sentir el encanto y el asombro, está prácticamente muerto. (1930, p. 194)

Más aún, mucho antes que Einstein, podemos encontrar en otro santo un apoyo a lo planteado. Hablaba en verdad san Juan de la Cruz cuando escribió en sus Coplas hechas sobre un éxtasis de harta contemplación:

Y, si lo queréis oír, consiste esta suma ciencia en un subido sentir de la divinal esencia; es obra de su clemencia hacer quedar no entendiendo, toda ciencia trascendiendo. (1855, p. 344) 


\section{Referencias}

Einstein, A. (1930). What I Believe. Forum and Century, 84(4), 193-194.

Francisco. (2013). Exhortación Apostólica Evangelii Gaudium del Santo Padre Francisco a los obispos, a los presbíteros y diáconos, a las personas consagradas y a los fieles laicos sobre el anuncio del evangelio en el mundo actual. Recuperado de http://w2.vatican. va/content/francesco/es/apost_exhortations/documents/papafrancesco_esortazione-ap_20131124_evangelii-gaudium.html

Francisco. (2013). Carta Encíclica Lumen Fidei del Sumo Pontífice Francisco a los obispos, a los presbíteros y diáconos, a las personas consagradas y a todos los fieles laicos sobre la fe. Recuperado de http://w2.vatican.va/content/francesco/es/encyclicals/documents/ papa-francesco_20130629_enciclica-lumen-fidei.html

Fondo Monetario Internacional. (octubre, 2014). Perspectivas de la economía mundial. Secuelas, nubarrones, incertidumbres. Recuperado de https://www.imf.org/external/spanish/pubs/ft/weo/2014/02/pdf/ texts.pdf

Juan Pablo II. (1990). Constitución Apostólica Ex Corde Ecclesiae sobre las Universidades Católicas. Recuperado de http://w2.vatican.va/ 
content/john-paul-ii/es/apost_constitutions/documents/hf_jp-ii_ apc_15081990_ex-corde-ecclesiae.html

San Juan de la Cruz. (1855). Coplas del mismo, hechas sobre un éxtasis de harta contemplación. En Sancha, J. de. Romancero y cancionero sagrados. Colección de poesías cristianas, morales y divinas, sacadas de las obras de los mejores ingenios españoles, por Don Justo de Sancha. Madrid, España: M. Rivadeneyra-Impresor-Editor.

V Conferencia General del Episcopado Latinoamericano y el Caribe. (2007). Documento de Aparecida. Recuperado de http://www.caritas. org.pe/documentos/documento_conclusivo_aparecida.pdf 